\title{
A versatile system for fast screening and isolation of Trichoderma reesei cellulase hyperproducers based on DsRed and fluorescence-assisted cell sorting
}

Fei Gao ${ }^{1,2}$, Zhenzhen Hao ${ }^{1}$, Xianhua Sun ${ }^{1}$, Lina Qin ${ }^{3}$, Tong Zhao ${ }^{3}$, Weiquan Liu², Huiying Luo ${ }^{1}$, Bin Yao ${ }^{*}$ and Xiaoyun Su${ }^{1 *}$

\begin{abstract}
Background: In the biofuel industry, cellulase plays an indispensable role in hydrolyzing cellulose into fermentable glucose. Trichoderma reesei is a popular filamentous fungus with prominent ability to produce cellulase. While classical mutagenesis and modern multiplex genome engineering are both effective ways to improve cellulase production, successful obtaining of strains with improved cellulase-producing ability requires screening a large number of strains, which is time-consuming and labor intensive.

Results: Herein, we developed a versatile method coupling expression of the red fluorescence protein (DsRed) in T. reesei and fluorescence-assisted cell sorting (FACS) of germinated spores. This method was first established by expressing DsRed intracellularly under the control of the major cellulase cbh1 promoter in T. reesei, which allowed us to rapidly isolate cellulase hyperproducers from $T$. reesei progenies transformed with a dedicated transcriptional activator ace 3 and from an atmospheric and room temperature plasma-created mutant T. reesei library. Since intracellularly expressed DsRed was expected to isolate mutations mainly affecting cellulase transcription, this method was further improved by displaying DsRed on the T. reesei cell surface, enabling isolation of strains with beneficial genetic alterations (overexpressing hacl and bip 1) affecting regulatory stages beyond transcription. Using this method, $T$. reesei cellulase hyperproducers were also successfully isolated from an Agrobacterium-mediated random insertional mutant library.
\end{abstract}

Conclusions: The coupled DsRed-FACS high-throughput screening method proved to be an effective strategy for fast isolation of $T$. reesei cellulase hyperproducers and could also be applied in other industrially important filamentous fungi.

Keywords: Trichoderma reesei, DsRed, FACS, Cellulase, High-throughput screening

\footnotetext{
*Correspondence: binyao@caas.cn; suxiaoyun@caas.cn

${ }^{1}$ Key Laboratory for Feed Biotechnology of the Ministry of Agriculture, Feed Research Institute, Chinese Academy of Agricultural Sciences, No. 12 South Zhongguancun Street, Beijing 100081, People's Republic of China Full list of author information is available at the end of the article
} 


\section{Background}

Trichoderma reesei is a saprophytic wood-decaying filamentous fungus with prominent ability to produce cellulase. The maximal extracellular protein concentration of T. reesei cellulase has been reported to reach $100 \mathrm{~g} / \mathrm{L}$ [1]. This ascomycete is, therefore, also regarded as a promising host for producing heterologous proteins. Indeed, a vast number of valuable enzymes and pharmaceutical proteins have been produced in this organism, which includes the Phlebia radiate laccase [2], Hormoconis resinae glucoamylase [3], barley endopeptidase B [4], Aspergillus niger acid phosphatase [5], lipase [6], glucose oxidase [7], endo-mannanase [8], antibodies, and interferons $[9,10]$.

On the route towards lignocellulosic biofuels, cellulase plays an indispensable role by hydrolyzing cellulose into fermentable glucose. T. reesei has long been used to produce cellulase and currently is still one popular microbe [11]. Varying strategies have been utilized to improve cellulase production in $T$. reesei, mainly by engineering the $T$. reesei strains and modifying the fermentation processes. Cellulase (and other kinds of enzymes or proteins) is synthesized from amino acid precursors. Therefore, the concept of metabolic engineering can be employed to improve cellulase expression and secretion in $T$. reesei basically by means of random mutagenesis and genetic engineering [12]. To improve production of cellulase widely useful in the biofuel industries, chemical and physical mutagenesis were initially carried out, which successfully generated hyperproducer mutants such as RUT-C30 [13] and CL-847 [14]. Additionally, Agrobacterium-mediated random insertional disruption of chromosomal genes was also successful in generating T. reesei hyperproducers [15]. Genetic engineering by overexpressing selected genes stimulating cellulase expression $[7,16]$ and removing the ones repressing cellulase expression $[17,18]$ controlling transcription, translation, and secretion as well as intracellular redox balance and cell metabolism [19-22] have become two common strategies to improve cellulase production in $T$. reese . It is noticed that multiplex genome engineering, i.e., manipulating more than one gene at a time, creates rich biological diversity from which a cellulase hyperproducer can be isolated [16]. By including more genes to manipulate, this biodiversity may even ascend, increasing the possibility to obtain hyperproducers. However, the concurring higher complexity demands a larger amount of transformants to be analyzed.

Both random mutagenesis and genetic engineering methods require considerable time and labor in screening. For T. reesei, this challenge is further complicated by the facts that $T$. reesei is multicellular and filamentous, cellulase is extracellularly expressed, and integration site and copy numbers largely affect gene expression level [23-25]. These characters dwarfed the endeavors to establish high-throughput screening methods. Coupling expression of green fluorescence protein (GFP) and fluorescence-assisted cell sorting (FACS) achieved isolation of $T$. reesei cellulase hyperproducers rapidly [26]. However, the expression of GFP is not easily observed without a fluorescence microscope. More importantly, this method cannot identify genetic alterations favoring improved secretion, which is elegantly regulated, but critical for cellulase expression [22, 27]. On the other hand, time can also be saved by scaling down from traditional shake flask to microtiter plate culture; however, the quantity of strains to be screened is still large [28]. Herein, we sought to overcome these bottlenecks and establish a new high-throughput screening method Specifically, we used the red fluorescence protein DsRed as a reporter molecule and demonstrated that the intracellularly expressed, and more importantly, surface-displayed DsRed coupled with FACS can be used for high-throughput screening of cellulase hyperproducers from $T$. reese $i$ progeny libraries generated by random mutagenesis or genetic engineering. It is expected that our results may provide a robust engineering framework for future efforts to engineer $T$. reesei, and other industrially important filamentous fungi as well, for enhanced secretion of cellulase and other valuable proteins.

\section{Results \\ Constructing the plasmids for intracellular expression and surface-display of DsRed}

DsRed is a coral red fluorescence protein with an excitation wavelength of $558 \mathrm{~nm}$ and an emission wavelength of $583 \mathrm{~nm}$, respectively [29]. To correlate the expression of DsRed to that of the T. reesei cellulase, the DsRed gene should be placed under the control of a major cellulase promoter. Cellobiohydrolase I (CBH1) is the highest expressed cellulase in $T$. reesei, accounting up to $50-60 \%$ of secreted proteins. Therefore, the codonoptimized DsRed gene was ligated downstream of the strong inducible $c b h 1$ promoter for intracellular expression (Fig. 1a). Surface-display of proteins has been frequently studied in bacteria [30] and yeasts [31], but gains much less attention in filamentous fungi. The Aspergillus fumigatus MP1 (AfMP1) is a cell wall-attached galactomanno-protein with a clearly defined C-terminal glycosylphosphatidylinositol (GPI) anchor signal sequence [32]. For surface-display of DsRed, the genes encoding the CBH1 signal peptide, DsRed, and the AfMP1 GPI anchor signal (GGSGSGSGSSTGTATASTSTNLLSTGAASKEHFSYSLGGAVVAAAIAVA) were in-frame fused. The chimeric gene was also placed between the $c b h 1$ promoter and terminator (Fig. 1b). 

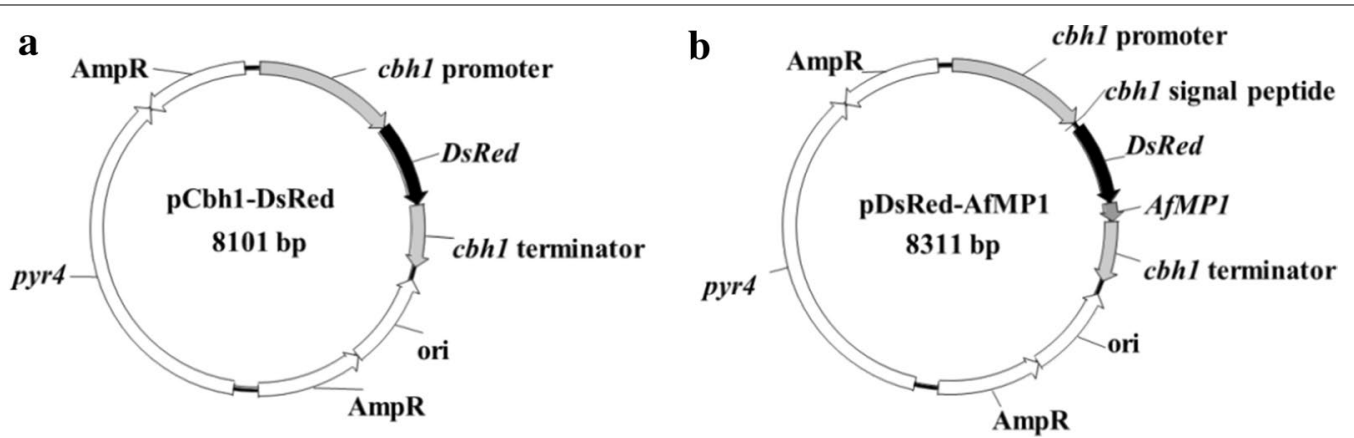

Fig. 1 Schematic diagrams of the plasmids for expressing DsRed. a The pCbh1-DsRed plasmid for expressing DsRed intracellularly. b The pDsRed-AfMP1 plasmid for displaying DsRed on T. reesei cell surface. For both plasmids, the strong inductive cbh1 promoter was used. AfMP1: the C-terminal GPI anchor from the A. fumigatus MP1 protein

\section{Intracellular expression of DsRed dictates isolation of genetically engineered $T$. reesei cellulase hyperproducers}

The plasmid encoding the codon-optimized DsRed under the control of $c b h 1$ promoter was transformed into $T$. reesei SUS2. DsRed was successfully expressed in T. reesei and red fluorescence appeared to be evenly distributed in the hyphae cytosome, which could be clearly visualized under fluorescence microscope (Fig. 2A). High level expression of DsRed resulted into change of the colony color from pale white to red on a MM-lactose plate, which could even be observed by naked eyes (Additional file 1). Next, we tested whether higher level of DsRed expression incurred by genetic modification of $T$. reese $i$ would be positively correlated with higher cellulase production. For this purpose, the transcriptional activator ace 3 was constructed downstream of the strong constitutive $p d c 1$ promoter to obtain pPdc1-ace3 (Additional file 2). This plasmid was transformed into a uridine-auxotrophic derivative of the DsRed-expressing SUS2 transformant, namely SUS3. Note that SUS2 and SUS3 have nearly identical cellulase-producing abilities (data not shown). Overexpression of ace 3 is known to stimulate cellulase expression in $T$. reesei by two- to fourfold [21]. Thus, 40 spores with highest red fluorescence signal (top $0.1 \%$ ) were collected for further analyses (Fig. 2B). Since SUS3 (and its parent strain SUS2) is a dedicated strain for egl2- overexpression, we measured the endoglucanase activity and used it as a cellulase indicator. All these selected ace3-transformants behaved better in preliminary flask fermentation, producing more endoglucanase as well as extracellular proteins (Fig. 2C).

SUS2 and four representative ace3-transformants with moderately to highly enhanced cellulase-producing ability were grown on cellulose plates for comparison of halos (an indicator of cellulose hydrolysis rate, roughly representing the cellulase activity). All ace3-transformants formed a halo (diameter: $3.50-3.95 \mathrm{~cm}$ ) larger than that of SUS2 (diameter: $3.20 \mathrm{~cm}$ ), indicative of improved cellulase producing ability (Fig. 2D). In flask fermentation, these four strains exhibited higher endoglucanase activities and protein concentrations from day 3 post-Avicel induction (Fig. 2E, F). These results indicated that the intracellular expressed DsRed under the control of $c b h 1$ promoter could be used to dictate selection of the T. reesei high cellulase producers. Using quantitative PCR, the gene copy numbers of ace 3 in the four transformants were determined to be two for SUS3-A11, SUS3-A19, and SUS3-A20 and three for SUS3-A27, higher than one in the parental strain (data not shown).

\section{Rapid isolation of $T$. reesei cellulase hyperproducers generated from ARTP random mutagenesis}

Through successful isolation of ace3-transformants with improved cellulase producing ability, the validity of the high-throughput screening method was demonstrated. However, we realized that random mutagenesis has been used as an effective way for $T$. reesei strain improvement [14] and is still being used widely. Indeed, most industrial strains are mutagenized derivatives of the QM6a strain [13]. Therefore, we tested if this DsRed-based FACS method could also be used for isolation of cellulase hyperproducers from a randomly mutagenized $T$. reese $i$ library.

The atmospheric and room temperature plasma mutation system, or ARTP, uses radio-frequency atmosphericpressure glow discharge plasma jets to create mutations in the DNA sequence and has been used to mutate more than 40 kinds of microorganisms including bacteria, fungi, and microalgae [33]. SUS3-A27, the best strain of the ace3-transformants, was used for mutagenesis. The ARTP-treated spores were grown for $14 \mathrm{~h}$ in MMlactose/sophorose liquid medium for germination. This culture period allows expression of cellulase genes (and 


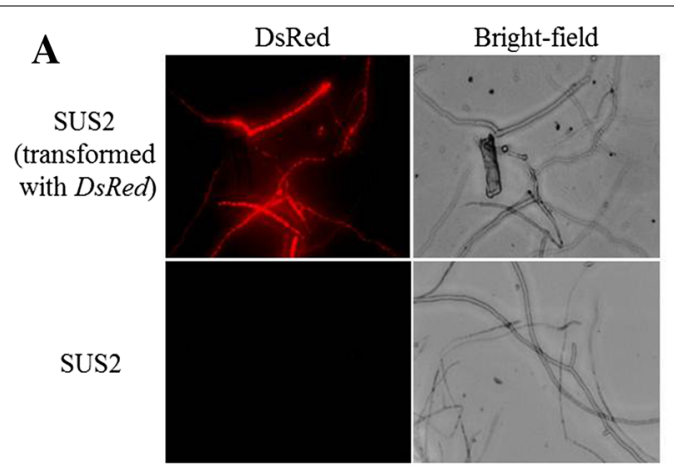

B
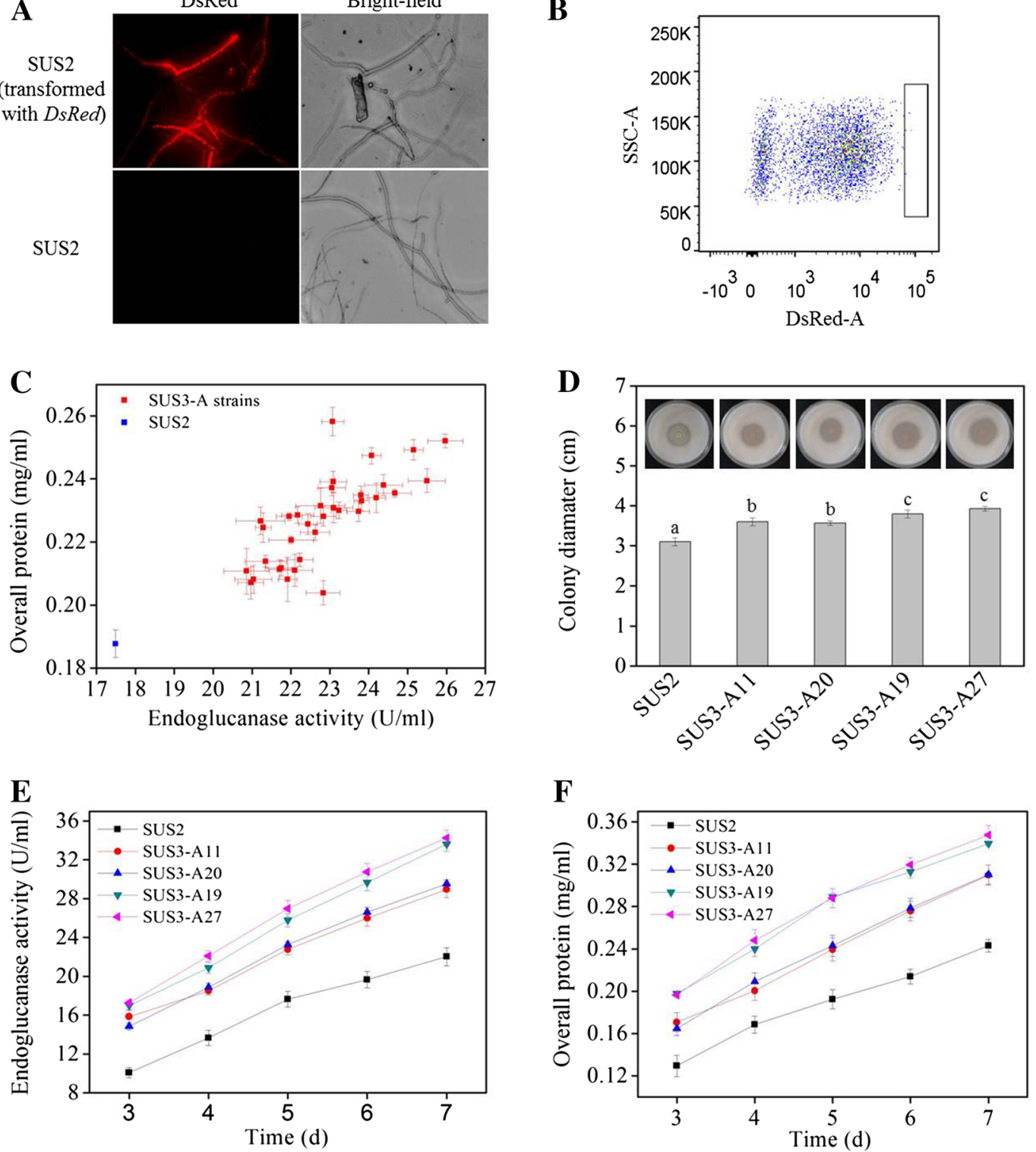

Fig. 2 Isolation of cellulase hyperproducers from ace3-transformants by FACS using the intracellularly expressing DsRed as an indicator. A Microscopic observation of the hyphae of T. reesei expressing intracellular DsRed and its parental strain SUS2. Mycelia were harvested from T. reesei cultivated at $28^{\circ} \mathrm{C}$ for $24 \mathrm{~h}$ in MM-lactose/sophorose. B Flow cytometry sorting of germlings with the brightest DsRed signal (top $0.1 \%$ ) from ace3-transformants. The area in box was the gating strategy used to delineate the brightest DsRed signal cell populations. C Preliminary assessment of endoglucanase producing and protein secretion ability of ace3-transformants in shake flask fermentation. D The cellulose-hydrolyzing halos formed by isolated representative ace3-transformants. Different letters $\left({ }^{a}, b\right.$, and $\left.{ }^{c}\right)$ mean that there are significant difference between the colony diameters $(p<0.05)$. E, F Representative ace3-transformants isolated in FACS produced more endoglucanase $(\mathbf{E})$ and secreted more proteins $(\mathbf{F})$

here DsRed also) [34] but precludes formation of long intertwining hyphae clog, which would be troublesome for flow cytometry analysis. Fifty-one germinated spores with highest red fluorescence signals were picked out from FACS (Fig. 3A). Unlike the ace3-transformation, some of the sorted mutants behaved poorer than the parent strain in the preliminary screening in flask cultivation
(Fig. 3A). This indicated that, stronger red fluorescence signal at the early stage of germination for these mutants from random mutagenesis do not necessarily parallel with higher cellulase producing ability. In spite of this inconsistence, certain mutants exhibited higher cellulase activity as well as overall protein concentrations than those of the parent strain (Fig. 3A). Three representative 


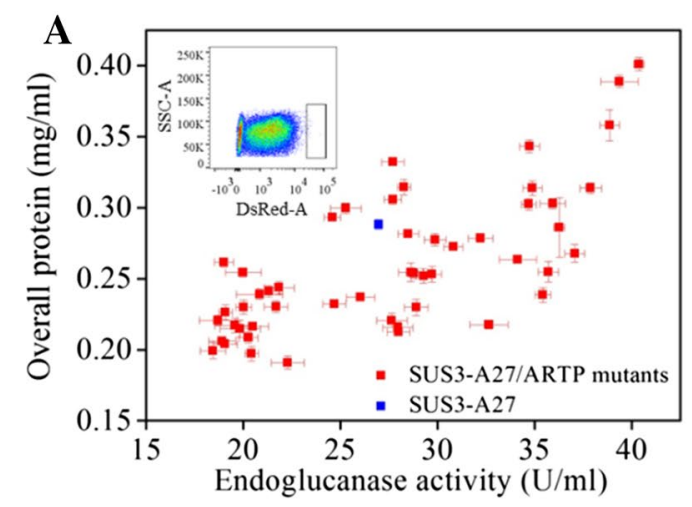

C

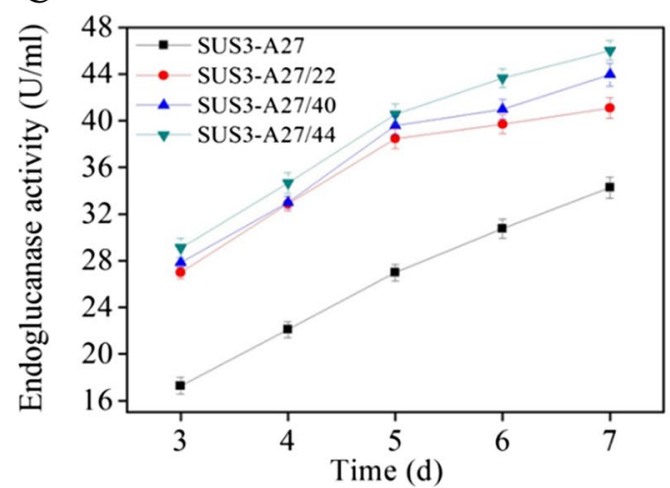

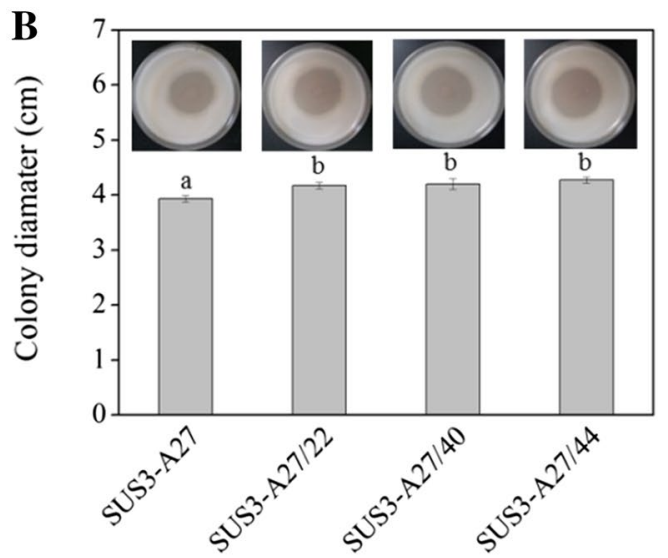

D

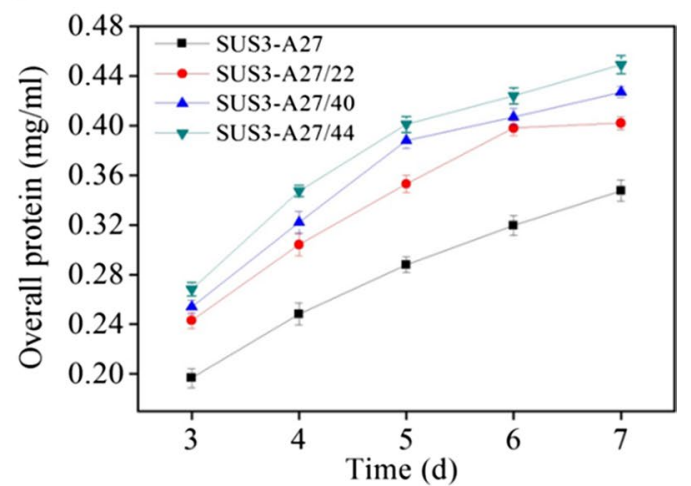

Fig. 3 Isolation of cellulase hyperproducers from an ARTP-generated T. reesei mutant library using FACS directed by intracellularly expressed DsRed. A Preliminary assessment of endoglucanase producing and protein secretion ability of isolated T. reesei strains. The T. reesei spores were mutagenized using ARTP. Germinated spores with the brightest DsRed signal (top $0.1 \%$ ) were isolated by FACS (internal illustration). The area in box was the gating strategy used to delineate the brightest DsRed signal cell populations. B Representative ARTP-mutagenized strains isolated by FACS displayed larger cellulose hydrolysis halos than the parent strain. Different letters $\left({ }^{(a}\right.$ and $\left.{ }^{b}\right)$ mean that there are significant difference between the colony diameters $(p<0.05)$. C, D Representative ARTP-mutagenized strains isolated by FACS produced more endoglucanase $(\mathbf{C})$ and secreted more proteins (D)

mutant strains (SUS3-A27/22, SUS3-A27/40, and SUS3A27/44) were used for further detailed analyses. These mutants formed cellulose-hydrolyzing halos with a diameter of $4.15-4.30 \mathrm{~cm}$, respectively, larger than that of SUS3-A27 $(3.95 \mathrm{~cm})$ on MM-Avicel plate (Fig. 3B). In addition, on the 7th day post-induction, SUS3-A27/22, SUS3-A27/40, and SUS3-A27/44 produced 41.1, 43.9, and $46.0 \mathrm{U} / \mathrm{ml}$ endoglucanase and $0.41,0.43$, and $0.45 \mathrm{mg} / \mathrm{ml}$ extracellular proteins, respectively, which were all higher than the values of SUS3-A27 $(34.2 \mathrm{U} / \mathrm{ml}$ for endoglucanase activity, Fig. $3 \mathrm{C}$ ) and $0.35 \mathrm{mg} / \mathrm{ml}$ (for extracellular protein concentration, Fig. 3D).

\section{Surface-display of DsRed enabled identifying genetic alterations beneficial for cellulase secretion}

The intracellularly expressed DsRed hardly allows identification of beneficial mutations or genetic modifications affecting the stages beyond transcription. However, this obstacle could be overcome if the expressed DsRed reporter protein also undergoes the secretory pathway while being attached to the cell. This can be achieved by displaying DsRed on the $T$. reesei cell surface. For this purpose, we fused the DsRed gene in frame between the sequences coding for the $\mathrm{CBH} 1$ signal peptide and AfMP1 GPI anchor. The CBH1 signal peptide will lead the DsRed protein through the secretory pathway and the covalently linked GPI anchor can keep DsRed attached to the cell surface. These traits are expected to facilitate high-throughput isolation of cellulase hyperproducers generated by genetic alterations at any regulatory stages.

The plasmid encoding the DsRed-AfMP1 chimeric gene was transformed into SUS2. The chimeric fluorescent protein was successfully expressed and correctly located because the hyphae were surrounded with red fluorescence (Fig. 4a). The display of DsRed-AfMP1 on T. reesei cell surface was further verified by sequentially 

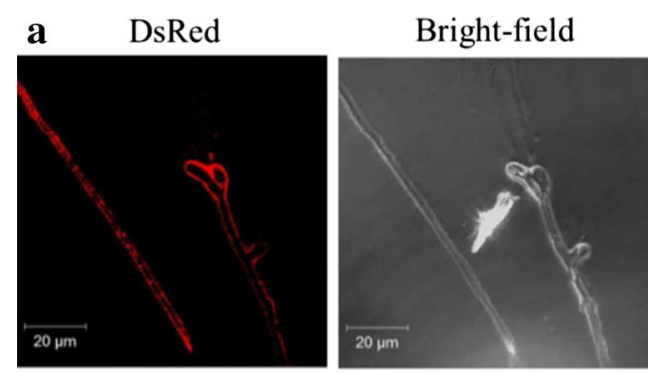

b
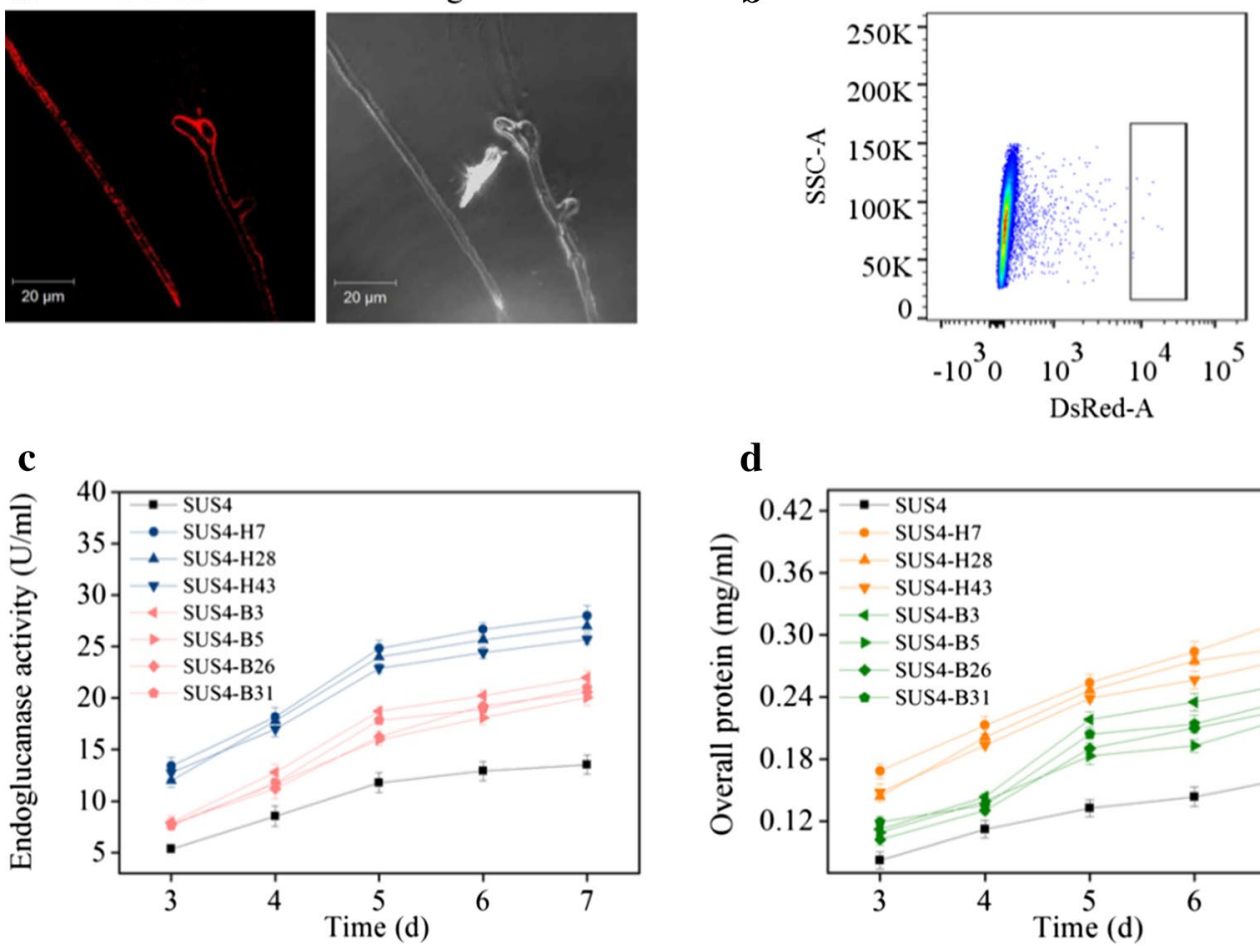

\section{d}

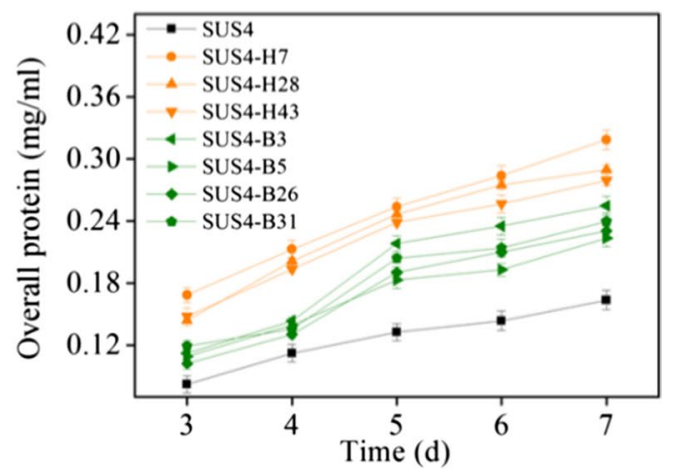

Fig. 4 Isolation of cellulase hyperproducers from T. reesei transformed with a mixture of six plasmids by FACS directed by surface-displayed DsRed. a Microscopic observation of the T. reesei hyphae displaying DsRed on cell surface. T. reesei was cultivated at $28^{\circ} \mathrm{C}$ for $24 \mathrm{~h}$ in MM-lactose/sophorose. $\mathbf{b}$ FACS isolation of germinated spores from T. reesei surface-displaying DsRed. T. reesei was transformed with a pool of six plasmids for overexpressing bip 1, hac1, ftt1, sso2, sar1, and ypt1, respectively. Sixty germlings with the brightest DsRed signal (top 0.1\%) were isolated. The area in box was the gating strategy used to delineate the brightest DsRed signal cell populations. $\mathbf{c}$, $\mathbf{d}$ Representative strains isolated by FACS produced more endoglucanase (c) and secreted more proteins (d)

incubating the germinated transformant spores with a monoclonal antibody against DsRed and FITC-labeled goat anti-mouse secondary antibody followed by flow cytometry analyses of both DsRed and FITC signals (Additional file 3). One should note that the red fluorescence of the DsRed-AfMP1 transformant (SUS4) was weaker than that expressing intracellular DsRed. This was also reflected by the color change of the DsRed-AfMP1transformant (Additional file 1). To analyze if surface-displayed DsRed could be used to screen beneficial genetic alterations at stages beyond transcription, six genes (bip1, hac1, ftt1, sso2, sar1, and ypt1) regulating cellulase folding and secretion were constructed into plasmids individually under strong constitutive promoters. Bip1 is an ER-resident molecular chaperone assisting folding of nascent proteins, while Hac1 is a global transcription regulator controlling the unfolded protein response [35]. Ftt1, Sso2, Sar1, and Ypt1 are proteins involved in diverse stages of the cellulase secretion pathway in T. reesei [22]. Equal amounts of the six plasmids were combined and one-time transformed into a uridine auxotroph of SUS4. The transformant spores were pooled for FACS. Sixty spores with the highest red fluorescence signal were collected (Fig. 4b). Seven representative strains were determined to produce more cellulase (Fig. 4c) and extracellular proteins (Fig. 4d). Interestingly, we discovered by PCR that these strains were transformants overexpressing hac1 and bip1 only but not the other four genes (data not shown). Quantitative PCR analysis indicated that 2 to 3 copies of hac1 (Fig. 5a) and bip1 (Fig. 5b) genes were existent in these transformants while there was only one copy in the parent strain (data not shown). The RTqPCR analysis further proved that both the bip1 and hac1 genes were transcribed to levels as high as 2.5- to 3.6-fold (hac1, Fig. 5c) and 3.5- to 8.2-fold (bip1, Fig. 5d) in these transformants.

\section{Isolation of cellulase hyperproducers from an insertional mutagenesis library of $T$. reesei aided by surface-displayed DsRed and FACS}

Agrobacterium-mediated transformation was used to randomly insert the pyr4 gene into the chromosome of the uridine auxotroph of SUS4. It was expected that, when the function of a gene negatively affecting cellulase 

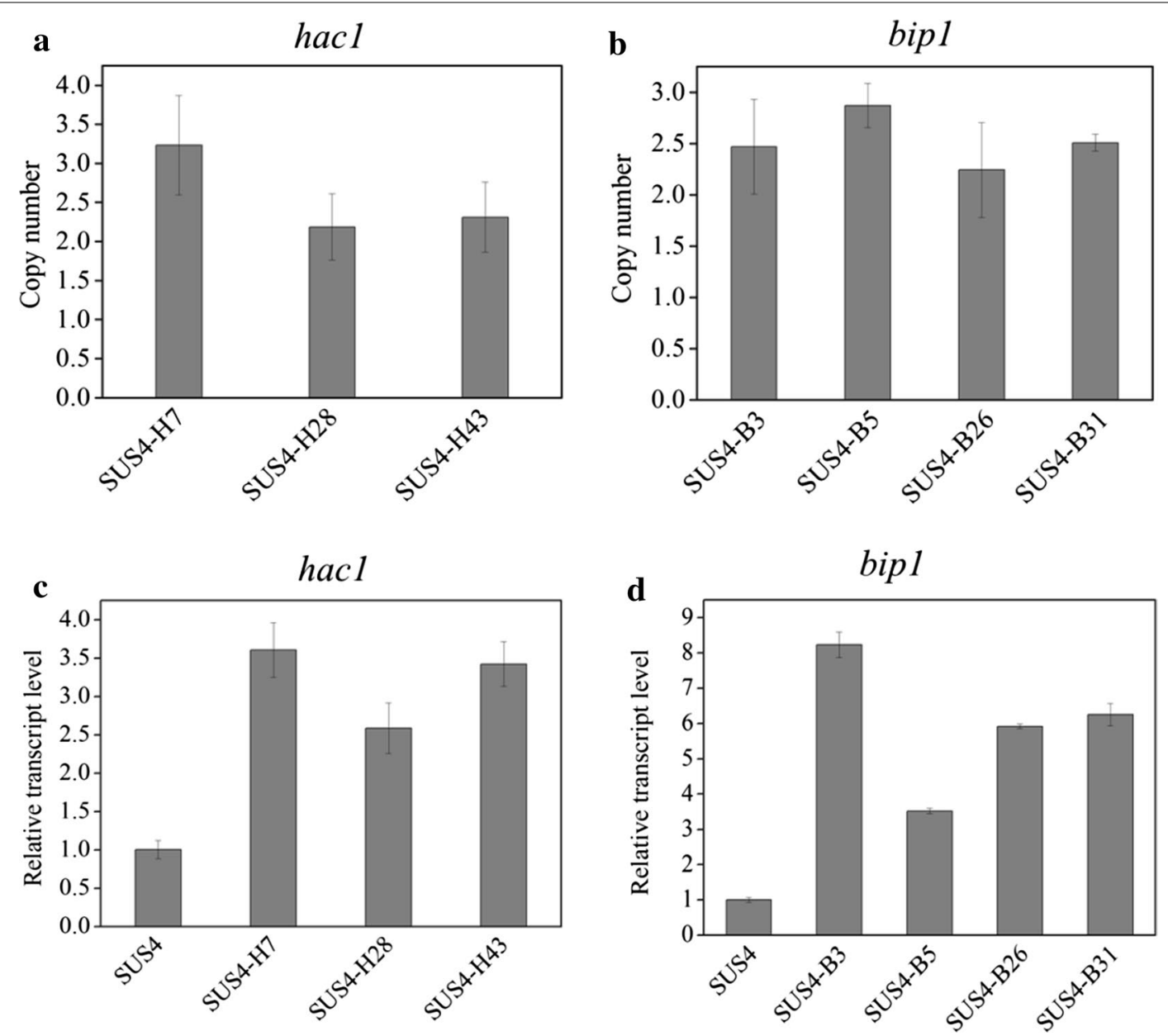

Fig. 5 Identification of hac1-and bip1-overexpression in isolated transformants with improved cellulase-producing ability. a, b Copy numbers of hacl (a) and bipl (b) in the transformants as determined by quantitative PCR. The expressing cassettes for only hacl or bip 1, but not the other four genes, were found in the seven strains with improved cellulase-producing ability. $\mathbf{c}$, $\mathbf{d}$ The relative transcript levels of hacl (c) and bip 1 (d) in these transformants as analyzed by RT-qPCR

expression was disrupted, the recombinant strain would display a cellulase hyperproducer phenotype. The spores from the transformants were pooled, germinated in MMlactose/sophorose, and sorted by FACS to obtain sixty spores with highest red fluorescence. In shake flask fermentation, four representative strains displayed higher endoglucanase activities (26.3-33.3 U/ml, Fig. 6a) and extracellular protein concentration $(0.29-0.32 \mathrm{mg} / \mathrm{ml}$, Fig. $6 \mathrm{~b})$ than those of the parent strain $(11.1 \mathrm{U} / \mathrm{ml}$ and $0.15 \mathrm{mg} / \mathrm{ml}$, respectively) at the end of fermentation.

\section{Discussion}

As a response to the lack of easy-to-ferment sugars such as glucose, $T$. reesei secrets cellulase which enables it to acquire carbon and energy from its natural habitat. Biosynthesis of cellulase is complex: induction of cellulase in T. reesei is well acknowledged to entail formation of sophorose, but very likely other oligo- or mono-saccharides, as well [12]. Numerous glycoside hydrolases, metabolic enzymes, transcription factors, signaling proteins, and secretory factors have, therefore, been discovered to be involved in initiating cellulase induction. Being glycoside hydrolases, cellulase can also be regarded as a special, excreted polypeptide metabolite. This implies that the availability of amino acid precursors and the intracellular redox and metabolic balance will also have a significant impact on cellulase biosynthesis and secretion [36]. These pieces of newly uncovered knowledge present unprecedented opportunities to modify $T$. reese $i$ for improved cellulase production. Random mutagenesis, genetic engineering (particularly multiplex genome engineering), or even directed evolution of key regulatory 

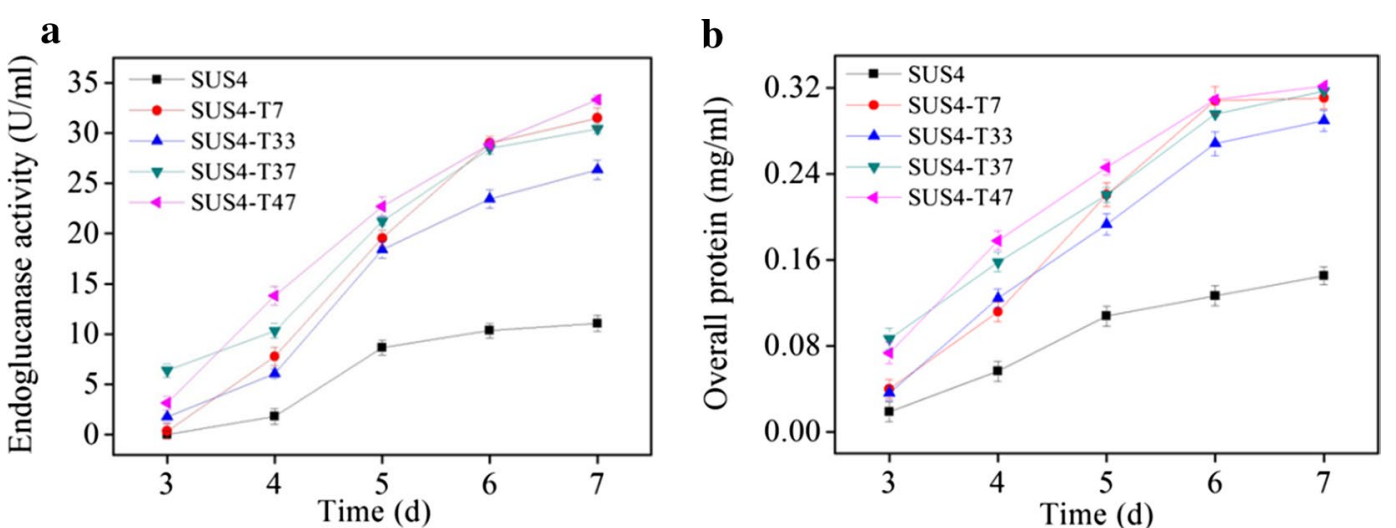

Fig. 6 Isolation of cellulase hyperproducers from a T. reesei mutant library created by Agrobacterium-mediated random insertion of the pyr4 gene in the chromosome. $\mathbf{a}$ Endoglucanase activity of the representative strains. $\mathbf{b}$ Extracellular protein concentrations of the representative strains

genes can all be potentially utilized in $T$. reesei for speeded strain improvement. However, all these endeavors require a high-throughput method as a prerequisite to isolate the cellulase hyperproducers.

The high-throughput method described herein for screening $T$. reesei cellulase hyperproducers was based on coupling the usage of DsRed and FACS. One advantage of DsRed is that the positive colonies turn to red, making them easily identified by naked eyes from the transformants (Additional file 1). Apparently, the depth of red color is positively associated with the inducing extent of cbh1 promoter. Using this system, we demonstrated as proof-of-concept that cellulase hyperproducers could be isolated from ace3-transformants and from a mutagenized library. Cellulose plate assay and preliminary shake flask fermentation confirmed the effectiveness of this method with the number of colonies largely reduced to as few as $\sim 50$, saving tremendous time and labor than the previous screening method [14]. Despite these successes, expressing DsRed intracellularly is limited to discovery of genetic modifications majorly favoring transcription, in sharp contrast with the complex nature of cellulase expression regulation in $T$. reesei $[37,38]$. Therefore, we overcome this hurdle by further developing a surfacedisplay technology of DsRed and demonstrated that the updated method managed to isolate beneficial genetic modifications (hac1- and bip1-overexpression) favoring nascent protein folding and secretion. The overexpressing cassettes for sso2, ftt1, sar1, and ypt1 could not be amplified from the isolated cellulase hyperproducers. It is possible that the expression of these genes may not be a bottleneck for cellulase expression in the investigated strain and under the specific culture condition. However, it could also be that the cellulase hyperproducers bearing one of these genes occasionally escaped the FACS isolation in the current study. These hypotheses undoubtedly need further investigations.

Different from small metabolites whose production can be either auto-regulated [39] or monitored by biosensor-based screening [40], cellulase is a secreted, special metabolite which cannot be readily quantified using any known, existent biosensors. Coupling DsRed-AfMP1 expression with FACS passes this barrier, enabling fast isolation of $T$. reesei cellulase hyperproducers from both engineered and mutagenized libraries. We noticed that, however, expression of DsRed-AfMP1 chimera reduced cellulase secretion in the host strain, suggesting that DsRed-AfMP1 might compete with the endogenous cellulase for the same secretory pathway. This trait is undesirable from the perspective of strain improvement. However, with this surface-display system, the impaired T. reesei can be quickly improved back to normal or even to a higher level of production after one or a few rounds of engineering. Moreover, once the strain is modified to reach a satisfying level of cellulase production, the expression of DsRed can be easily eliminated using the RNAi-mediated gene silencing [6] or gene knockout using the CRISPR/Cas9 system [41], further releasing the occupied carbon, energy, and secretion pathway components for cellulase.

At this time, the relationship of the sugar utilization metabolic pathways or redox balance to cellulase induction in $T$. reesei is still not clear, preventing us from testing the efficacy of this system to obtain cellulase hyperproducers by engineering these metabolic processes. It is also not known to what extent DsRed and cellulase share the expression and secretory machineries. The current system can thus be further improved by constructing a modified DsRed-AfMP1 chimeric protein by fusing DsRed to the C-terminus of a major cellulase 
(CBH1, CBH2, EG1, or EG2) [42], whose mode of secretion is expected to be much more similar to that of the cellulase. With slight modifications, this versatile system can also be used for strain improvement to produce heterologous proteins in $T$. reesei. Moreover, the use of the red fluorescence protein, particularly in a surfacedisplayed form, coupled with FACS, can also be easily implanted to other industrially important protein producing filamentous fungi such as Aspergillus oryzae [43], A. niger [44], Neurospora crassa [45], and Myceliophthora thermophila [46].

\section{Conclusions}

In this study, we established a high-throughput method for fast isolation of $T$. reesei cellulase hyperproducers. Specifically, coupling expression of DsRed with FACS allowed us to rapidly isolate cellulase hyperproducers from ace3-transformants and from a random mutagenized $T$. reesei library. Furthermore, displaying DsRed on T. reesei cell surface enabled isolation of cellulase hyperproducers with genetic variations for enhanced expression of proteins involved in nascent protein folding and secretion (bip1 and hac1) beyond transcription. This versatile system saves tremendous time and labor than the previous screening methods and can, therefore, be used as a robust engineering framework for future metabolic engineering of $T$. reesei, as well other industrially important filamentous fungi for enhanced secretion of cellulase and other valuable proteins.

\section{Methods}

\section{Strains, plasmids, and culture conditions}

The Escherichia coli Trans I-T1 strain from Transgen (Beijing, China) was used as a host for plasmid construction and propagation. The Saccharomyces cerevisiae AH109 (Clontech, San Francisco, CA) auxotrophic strain was used as the host for constructing the plasmids containing the expressing cassettes via DNA assembler [47]. The T. reesei SUS2 strain is uridine-auxotrophic and derived from SUS1 [8] by transforming extra copies of the endogenous cel5A (egl2) gene under control of the cbh1 promoter. The Agrobacterium tumefaciens AGL-1 strain was used as the T-DNA donor for A. tumefaciens-mediated transformation (AMT) of T. reesei. The plasmids containing the codon-optimized DsRed gene (pSKLR) [25] and the AfMP1 gene (pGFP-Mp1) [32] are kindly gifts from Prof. Zhiyang Dong and Haomiao Ouyang, respectively, from the Institute of Microbiology Chinese Academy of Sciences. The plasmid pTi was provided by Dr. XinXin Xu from Biotechnology Research Institute, Chinese Academy of Agricultural Sciences.

The $E$. coli and $A$. tumefaciens were cultured in the Luria-Bertani (LB) medium supplemented with an appropriate antibiotic when needed. The yeast AH109 strain was cultivated in yeast peptone dextrose medium with adenine (YPDA) at $30{ }^{\circ} \mathrm{C}$. T. reesei was grown on potato dextrose agar (PDA) at $28{ }^{\circ} \mathrm{C}$ for sporulation. For cellulase production, $T$. reesei was first grown in minimal medium (MM) $\left(\left(\mathrm{NH}_{4}\right)_{2} \mathrm{SO}_{4}, 5.0 \mathrm{~g} / \mathrm{L} ; \mathrm{KH}_{2} \mathrm{PO}_{4}, 15 \mathrm{~g} / \mathrm{L}\right.$; $\mathrm{MgSO}_{4}, 0.6 \mathrm{~g} / \mathrm{L} ; \mathrm{CaCl}_{2}, 0.6 \mathrm{~g} / \mathrm{L} ; \mathrm{FeSO}_{4} \cdot 7 \mathrm{H}_{2} \mathrm{O}, 0.005 \mathrm{~g} / \mathrm{L}$; $\mathrm{MnSO}_{4} \cdot \mathrm{H}_{2} \mathrm{O}, 0.0016 \mathrm{~g} / \mathrm{L} ; \mathrm{ZnSO}_{4} \cdot 7 \mathrm{H}_{2} \mathrm{O}, 0.0014 \mathrm{~g} / \mathrm{L}$; $\mathrm{CoCl}_{2}, 0.002 \mathrm{~g} / \mathrm{L}$ ) supplemented with $2 \%$ glucose as the sole carbon source and then mycelia were transferred to the MM-2\% Avicel medium. The basal medium (BM), induction medium (IM), and co-cultivation medium (CM) used for AMT were prepared as described previously [48].

\section{Plasmid construction}

The DNA assembler method which utilizes the highly efficient in vivo homologous recombination machinery was employed in this study to construct the DsRedexpressing plasmid. The DsRed gene was amplified from pSKLR using the primer pairs DsRedF/R (Additional file 4). The $c b h 1$ promoter and terminator were amplified from the genomic DNA of TU-6 using the Trcbh1pF/R and $\operatorname{Trcbh} 1 \mathrm{tF} / \mathrm{R}$ primer pairs, respectively (Additional file 4). The EcoRI-linearized pRS424 plasmid was mixed with the $c b h 1$ promoter, DsRed, and $c b h 1$ terminator and co-transformed into S. cerevisiae AH109 to obtain pRSDsRed. The DsRed expressing cassette was amplified from pRS-DsRed using the primers DsRedcbh1F/R and inserted into the EcoRI and BamHI sites of the plasmid pAPA by Gibson assembly [49], which was constructed by inserting a marker gene pyr4 flanked by two tandemly repeated ampicillin resistance genes [8]. This resulted into pCbh1-DsRed for intracellular expression of DsRed. The direct repeats of ampicillin resistance genes were used for looping out the pyr4 selection marker gene in the $T$. reesei transformants when needed $[8,50]$. For surfacedisplay of DsRed, the AfMP1 GPI anchor gene was first fused to the $3^{\prime}$-end of DsRed gene (containing the gene encoding the $c b h 1$ signal peptide at the $5^{\prime}$-end) by overlap extension PCR using the primers SPcbh1-DsRedF/R and MP1F/R, respectively (Additional file 4). Then the DsRed$A f M P 1$ gene was assembled with the $c b h 1$ promoter and terminator and inserted into the pAPA plasmid to obtain pDsRed-AfMP1. The pPdc1-ace3 plasmid was constructed by the same method using the $p d c 1$ promoter and terminator (Table 1, Additional file 2). The expressing cassettes of six genes (sso2, ftt1, sar1, ypt1, bip1, and hac1) (Table 1) involved in nascent protein folding and secretion were amplified from our previously constructed plasmids [7] and ligated into pAPA. For AMTmediated insertional mutagenesis of $T$. reesei, the pyr4 gene was amplified from the genomic DNA of QM9414 
Table 1 The regulatory genes involved in cellulase expression in $T$. reesei under investigation in this study

\begin{tabular}{lllll}
\hline Gene & Function & Promoter $^{\mathbf{a}}$ & Terminator $^{\mathbf{a}}$ & References \\
\hline ace3 & Transcription activator & $p d c 1$ & $p d c 1$ & {$[22]$} \\
bip1 & Chaperone & enol & enol & {$[27]$} \\
hac1 & $\begin{array}{l}\text { Unfolded protein } \\
\text { response }\end{array}$ & enol & enol & {$[35]$} \\
ftt1 & Secretion & $p d c 1$ & $p d c 1$ & {$[54]$} \\
sso2 & t-SNARE protein & $p d c 1$ & $p d c 1$ & {$[22]$} \\
sar1 & Vesicle budding & gpd1 & gpd1 & {$[55]$} \\
ypt1 & Vesicle fusion & gpd1 & gpd1 & {$[56]$} \\
\hline
\end{tabular}

${ }^{a}$ The promoters and terminators used to control gene expression in this study

with the primer pairs pyr4F/R (Additional file 4) and ligated into the XmaJI and PacI restriction sites of the plasmid pTi using the ClonExpress ${ }^{\circledR}$ II One Step Cloning Kit (Vazyme, Nanjing, China) to obtain the plasmid pTipyr4 (Additional file 5).

\section{Transformation of $T$. reesei}

The plasmids were introduced into $T$. reesei using the polyethylene glycol (PEG)-mediated protoplast transformation method [51]. Briefly, T. reesei was grown in MM-glucose $(2 \%)$ at $30{ }^{\circ} \mathrm{C}$ for $24 \mathrm{~h}$. The young mycelia were collected, mixed with $10 \mathrm{mg} / \mathrm{ml}$ of Lysing Enzymes from Trichoderma harzianum (L1412, Sigma-Aldrich, St. Louis, MO), and frequently observed under microscope until large amounts of protoplasts were released. The uridine autotroph transformants were selected on MM-glucose plates and screened for integration of the expressing cassette into the chromosome of $T$. reese $i$ by PCR.

Agrobacterium-mediated transformation was used for insertional mutagenesis of $T$. reesei [52]. Briefly, A. tumefaciens containing the binary vector pTi-pyr4 was grown at $28{ }^{\circ} \mathrm{C}$ for 2 days in liquid BM supplemented with kanamycin $(50 \mu \mathrm{g} / \mathrm{ml})$. The bacterial cell suspensions were diluted to an optical density at $600 \mathrm{~nm}\left(\mathrm{OD}_{600}\right)$ of $0.2 \mathrm{in}$ IM with $200 \mu \mathrm{M}$ acetosyringone (AS) and grown for $6 \mathrm{~h}$ to an $\mathrm{OD}_{600}$ of 0.4-0.8. Equal volumes of $A$. tumefaciens cells and the T. reesei protoplasts $\left(10^{7} / \mathrm{ml}\right)$ were mixed. Next, $200 \mu \mathrm{l}$ of this blend were plated on a $90-\mathrm{mm}$ diameter cellophane paper on top of CM-agar in presence of $200 \mu \mathrm{M}$ AS. After co-cultivation at $25^{\circ} \mathrm{C}$ for $48 \mathrm{~h}$, the cellophane paper was transferred to the selection medium (BM-agar supplemented with $1 \mathrm{M}$ sorbitol and $200 \mu \mathrm{g} /$ $\mathrm{ml}$ cefotaxime but lacking uridine). The transformant colonies were transferred onto PDA for sporulation. The spores were mixed and used for FACS screening.

\section{Verification of DsRed-AfMP1 expression on T. reesei cell surface}

The T. reesei SUS2 and its DsRed-AfMP1 transformant spores were cultured in MM-lactose/sophorose ( $2 \%$ for lactose and $0.003 \%$ for sophorose, w/v) at $28{ }^{\circ} \mathrm{C}$ with agitation at $200 \mathrm{rpm}$ for $12 \mathrm{~h}$. The germinated spores were harvested by centrifugation at 10,000 rpm and washed twice with phosphate-buffered saline (PBS) containing $1 \mathrm{mg} / \mathrm{ml}$ bovine serum albumin (BSA). Cells were re-suspended in PBS containing $5 \mu \mathrm{g} / \mathrm{ml}$ of mouse antiDsRed monoclonal antibody (Abcam, Shanghai, China) and incubated at room temperature for $2 \mathrm{~h}$. The cells were washed again with PBS and incubated with $10 \mu \mathrm{g} /$ $\mathrm{ml}$ of fluorescein isothiocyanate (FITC)-labeled goat antimouse IgG secondary antibody (Abcam) for $1 \mathrm{~h}$. The cells were finally washed twice with PBS and passed through flow cytometry for analyses of both DsRed and FITC signals.

\section{ARTP-mediated mutagenesis of $T$. reesei}

For ARTP-mediated mutagenesis, T. reesei spores harvested from 5-day-old culture of the strain SUS3-A27 on PDA plate were suspended in distilled water to a concentration of $10^{9}$ per $\mathrm{ml}$. Ten $\mu \mathrm{l}$ of this spore suspension were spread on the surface of a sterilized sample plate and subjected to ARTP treatment. The radio-frequency power input was set as $100 \mathrm{~W}$ and the helium gas flow rate was 10 SLM (standard liter per minute) with a plasma action distance of $2 \mathrm{~mm}$. The processing time was set at $3 \mathrm{~min}$. After ARTP treatment, the spores were transferred to $1 \mathrm{ml}$ of distilled water. The spores were plated on PDA plates and allowed to grow for re-sporulation for 5-7 days. Finally, spores from these plates were mixed for FACS.

\section{FACS}

Fresh spores were inoculated into liquid MM-lactose/ sophorose ( $2 \%$ for lactose and $0.003 \%$ for sophorose, $\mathrm{w} / \mathrm{v}$ ) and cultured at $28^{\circ} \mathrm{C}$ with vigorous shaking for $14 \mathrm{~h}$. High-speed sorting was performed on a FACS Aria sorter at a rate of 5000 events per second, 30 psi with an $85 \mu \mathrm{m}$ nozzle. Single germlings with the brightest (top 0.1\%) DsRed signal were sorted into individual wells of 6-well plates and incubated at $28^{\circ} \mathrm{C}$ for sporulation.

\section{Induction of cellulase expression in T. reesei}

For shake flask fermentation, fresh spores $\left(1 \times 10^{7}\right)$ of $T$. reesei were individually inoculated into $50 \mathrm{ml}$ of liquid MM-glucose (2\%) and cultured at $28{ }^{\circ} \mathrm{C}$ with agitation at $200 \mathrm{rpm}$ for $48 \mathrm{~h}$. The mycelia were collected and washed twice with MM to remove residual glucose. One gram of the mycelia was then transferred to $100 \mathrm{ml}$ of MM-Avicel 
(2\%) for cellulase induction. The culture was continued at $28{ }^{\circ} \mathrm{C}$ for 7 days. From $72 \mathrm{~h}$ to $168 \mathrm{~h}$ post-induction, the culture supernatants were periodically sampled for assay of the cellulase activities and protein concentrations.

\section{Assay of endoglucanase activity and protein concentration} For assay of the endoglucanase activity, $900 \mu \mathrm{l}$ of $1 \%(\mathrm{w} / \mathrm{v})$ sodium carboxymethyl cellulose (CMC-Na, from SigmaAldrich) in the Mcllvaine buffer ( $\mathrm{pH}$ 5.0) were mixed with $100 \mu \mathrm{l}$ of appropriately diluted enzymes. The reaction was incubated at $50{ }^{\circ} \mathrm{C}$ for $10 \mathrm{~min}$ and the released reducing sugars were determined using the 3,5-dinitrosalicylic acid (DNS) method. One unit of endoglucanase activity was defined as the amount of enzyme that liberated $1 \mu \mathrm{mol}$ of reducing sugar per minute. The protein concentration was determined using the BCA-200 Protein Assay Kit (Pierce, Rockford, IL).

\section{Fungal growth and microcrystalline cellulose hydrolysis}

The $T$. reesei spores $\left(3 \times 10^{5}\right)$ were individually spotted on agar plates containing MM-Avicel (2\%) and incubated at $28{ }^{\circ} \mathrm{C}$ for $4-7$ days until halo around the colony could be clearly visualized. The halo diameters were measured and compared.

\section{Reverse transcription quantitative PCR analysis}

For reverse transcription quantitative PCR (RT-qPCR), the mycelia of $T$. reesei cultured in MM-Avicel (2\%) for $24 \mathrm{~h}$ were collected and pulverized in liquid nitrogen using a pestle and mortar. The total RNA was extracted using the TRIzol reagent (Thermo Fisher Scientific, Waltham, MA). The cDNA was synthesized using the First Strand cDNA Maxima Synthesis kit (TOYOBO, Shanghai, China). RT-qPCR was performed in an Applied Biosystems $^{\mathrm{TM}}{ }^{\text {QuantStudi }}{ }^{\mathrm{TM}} 6$ Flex Real-Time PCR System (Applied Biosystems, San Diego, CA) using a TransScript Green One-Step SuperMix (TransGen, Beijing, China). The actin gene was used as an endogenous reference. The primers used for RT-qPCR were listed in Additional file 4 . The following amplification conditions were used: $95{ }^{\circ} \mathrm{C}$ for $10 \mathrm{~min}$ for initial denaturation, 40 cycles of $94{ }^{\circ} \mathrm{C}$ for $10 \mathrm{~s}, 60^{\circ} \mathrm{C}$ for $20 \mathrm{~s}$, and $72{ }^{\circ} \mathrm{C}$ for $20 \mathrm{~s}$.

\section{Determining copy numbers by qPCR}

To determine the copy numbers of the integrated ace3, bip1 or hac1 gene in the transformants, the genomic DNA was extracted from the mycelia by a Fungal DNA kit (Omega bio-tek, USA) and used as the template for quantitative PCR (qPCR). The qPCR method was performed as that described by Solomon [53]. The cbh1 gene was used to represent a single copy gene. The qPCR was performed with the SYBR Green Real-time PCR
Master Mix (TOYOBO, Osaka, Japan) in a CFX96 RealTime PCR Detection System (Bio-Rad, Hercules, CA). The primers used for qPCR were also listed in Additional file 4. The qPCR conditions were: $94{ }^{\circ} \mathrm{C}$ for $30 \mathrm{~s}, 40$ cycles of $94{ }^{\circ} \mathrm{C}$ for $30 \mathrm{~s}, 6{ }^{\circ} \mathrm{C}$ for $30 \mathrm{~s}$, and $72{ }^{\circ} \mathrm{C}$ for $20 \mathrm{~s}$.

\section{Additional files}

\section{Additional file 1. Observation of representative T. reesei strains expressing DsRed by naked eyes. The culture medium is MM-lactose plus agar. \\ Additional file 2. Schematic diagram of pPdc1-ace3. \\ Additional file 3. Verification of DsRed-AfMP1 expression on T. reesei cell surface. \\ Additional file 4. Primers used in this study. \\ Additional file 5. Schematic diagram of pTi-pyr4. $L B$ left border, $R B$ right border.}

\section{Abbreviations}

FACS: fluorescence-assisted cell sorting; GFP: green fluorescence protein; AMT: Agrobacterium tumefaciens-mediated transformation; YPDA: yeast extract-peptone dextrose medium with adenine; PDA: potato dextrose agar; MM: minimal medium; BM: basal medium; IM: induction medium; CM: co-cultivation medium; AS: acetosyringone; ARTP: atmospheric and room temperature plasma; DNS: 3,5-dinitrosalicylic acid; $\mathrm{CBH1}$ : cellobiohydrolase I; $\mathrm{CBH}$ 2: cellobiohydrolase II; EG1: endoglucanase I; EG2: endoglucanase II; GPI: glycosylphosphatidylinositol; SLM: standard liter per minute.

\section{Authors' contributions}

FG performed research, analyzed data, and wrote the paper. ZH, XhS, and $\mathrm{HL}$ analyzed the data, LQ, TZ, and WL provided technical assistance, BY designed research, XS designed research, analyzed data, and wrote the paper. All authors read and approved the final manuscript.

\section{Author details}

${ }^{1}$ Key Laboratory for Feed Biotechnology of the Ministry of Agriculture, Feed Research Institute, Chinese Academy of Agricultural Sciences, No. 12 South Zhongguancun Street, Beijing 100081, People's Republic of China. ${ }^{2}$ College of Biological Sciences, China Agricultural University, Beijing 100193, China.

${ }^{3}$ Institute of Microbiology, Chinese Academy of Sciences, Beijing 100101, China.

\section{Competing interests}

The authors declare that they have no competing interests.

\section{Availability of supporting data}

All data supporting the conclusions of this article are included within the manuscript and additional files.

\section{Consent for publication}

All authors provide their consent for publication of their manuscript in Biotechnology for Biofuels.

\section{Ethics approval and consent to participate}

Not applicable.

\section{Funding}

This study was supported by the National Key R\&D Program of China (2016YFD0501409-02), the National Natural Science Foundation of China Grant 31672458, the Fundamental Research Funds for Central Non-profit Scientific Institution (1610382016004 and Y2017JC31), the National Chicken Industry Technology System of China (CARS-41), and the Elite Youth Program of Chinese Academy of Agricultural Sciences. 


\section{Publisher's Note}

Springer Nature remains neutral with regard to jurisdictional claims in published maps and institutional affiliations.

Received: 9 July 2018 Accepted: 19 September 2018 Published online: 24 September 2018

\section{References}

1. Cherry JR, Fidantsef AL. Directed evolution of industrial enzymes: an update. Curr Opin Biotechnol. 2003;14:438-43.

2. Saloheimo M, Niku-Paavola ML, Knowles JK. Isolation and structural analysis of the laccase gene from the lignin-degrading fungus Phlebia radiata. J Gen Microbiol. 1991;137:1537-44.

3. Joutsjoki VV, Torkkeli TK, Nevalainen KM. Transformation of Trichoderma reesei with the Hormoconis resinae glucoamylase P (gamP) gene: production of a heterologous glucoamylase by Trichoderma reesei. Curr Genet. 1993;24:223-8.

4. Saarelainen R, Mantyla A, Nevalainen H, Suominen P. Expression of barley endopeptidase B in Trichoderma reesei. Appl Environ Microbiol. 1997;63:4938-40

5. Miettinen-Oinonen A, Torkkeli T, Paloheimo M, Nevalainen H. Overexpression of the Aspergillus niger $\mathrm{pH} 2.5$ acid phosphatase gene in a heterologous host Trichoderma reesei. J Biotechnol. 1997;58:13-20.

6. Qin LN, Cai FR, Dong XR, Huang ZB, Tao Y, Huang JZ, Dong ZY. Improved production of heterologous lipase in Trichoderma reesei by RNAi mediated gene silencing of an endogenic highly expressed gene. Bioresour Technol. 2012;109:116-22.

7. Wu Y, Sun X, Xue X, Luo H, Yao B, Xie X, Su X. Overexpressing key component genes of the secretion pathway for enhanced secretion of an Aspergillus niger glucose oxidase in Trichoderma reesei. Enzyme Microb Technol. 2017;106:83-7.

8. Sun X, Xue X, Li M, Gao F, Hao Z, Huang H, Luo H, Qin L, Yao B, Su X. Efficient coproduction of mannanase and cellulase by the transformation of a codon-optimized endomannanase gene from Aspergillus niger into Trichoderma reesei. J Agric Food Chem. 2017;65:11046-53.

9. Landowski CP, Huuskonen A, Wahl R, Westerholm-Parvinen A, Kanerva A, Hanninen AL, Salovuori N, Penttila M, Natunen J, Ostermeier C, et al. Enabling low cost biopharmaceuticals: a systematic approach to delete proteases from a well-known protein production host Trichoderma reesei. PLOS ONE. 2015;10:e0134723.

10. Landowski CP, Mustalahti E, Wahl R, Croute L, Sivasiddarthan D, Westerholm-Parvinen A, Sommer B, Ostermeier C, Helk B, Saarinen J, Saloheimo M. Enabling low cost biopharmaceuticals: high level interferon $a-2 b$ production in Trichoderma reesei. Microb Cell Fact. 2016;15:104.

11. Garvey M, Klose H, Fischer R, Lambertz C, Commandeur U. Cellulases for biomass degradation: comparing recombinant cellulase expression platforms. Trends Biotechnol. 2013;31:581-93.

12. Kubicek CP, Mikus M, Schuster A, Schmoll M, Seiboth B. Metabolic engineering strategies for the improvement of cellulase production by Hypocrea jecorina. Biotechnol Biofuels. 2009;2:19.

13. Peterson R, Nevalainen $H$. Trichoderma reesei RUT-C30-thirty years of strain improvement. Microbiology. 2012;158:58-68.

14. Durand H, Clanet M, Tiraby G. Genetic improvement of Trichoderma reesei for large scale cellulase production. Enzyme Microb Technol. 1988;10:341-6

15. Zhong $Y H$, Wang $X L$, Yu HN, Liang SR, Wang TH. Application of T-DNA insertional mutagenesis for improving cellulase production in the filamentous fungus Trichoderma reesei. Bioresour Technol. 2012;110:572-7.

16. Wang S, Liu G, Wang J, Yu J, Huang B, Xing M. Enhancing cellulase production in Trichoderma reesei RUT C30 through combined manipulation of activating and repressing genes. J Ind Microbiol Biot. 2013;40:633-41.

17. Nakari-Setala T, Paloheimo M, Kallio J, Vehmaanpera J, Penttila M, Saloheimo M. Genetic modification of carbon catabolite repression in Trichoderma reesei for improved protein production. Appl Environ Microbiol. 2009;75:4853-60

18. Chen F, Chen X, Su X, Qin L, Huang Z, Tao Y, Dong Z. An Ime2-like mitogen-activated protein kinase is involved in cellulase expression in the filamentous fungus Trichoderma reesei. Biotechnol Lett. 2015;37:2055-62.
19. Strauss J, Mach RL, Zeilinger S, Hartler G, Stoffler G, Wolschek M, Kubicek CP. Cre1, the carbon catabolite repressor protein from Trichoderma reesei. FEBS Lett. 1995:376:103-7.

20. Aro N, Saloheimo A, IImen M, Penttila M. ACEll, a novel transcriptional activator involved in regulation of cellulase and xylanase genes of Trichoderma reesei. J Biol Chem. 2001;276:24309-14.

21. Hakkinen M, Valkonen MJ, Westerholm-Parvinen A, Aro N, Arvas M, Vitikainen M, Penttila M, Saloheimo M, Pakula TM. Screening of candidate regulators for cellulase and hemicellulase production in Trichoderma reesei and identification of a factor essential for cellulase production. Biotechnol Biofuels. 2014;7:14.

22. Saloheimo M, Pakula TM. The cargo and the transport system: secreted proteins and protein secretion in Trichoderma reesei (Hypocrea jecorina). Microbiology. 2012;158:46-57.

23. Jeenes DJ, Mackenzie DA, Roberts IN, Archer DB. Heterologous protein production by filamentous fungi. Biotechnol Genet Eng Rev. 1991;9:327-67

24. Harkki A, Uusitalo J, Bailey M, Penttila ME, Knowles JKC. A novel fungal expression system: secretion of active calf chymosin from the filamentous fungi Trichoderma reesei. Nat Biotechnol. 1989;7:596-603.

25. Qin L, Jiang X, Dong Z, Huang J, Chen X. Identification of two integration sites in favor of transgene expression in Trichoderma reesei. Biotechnol Biofuels. 2018;11:142

26. Throndset W, Kim S, Bower B, Lantz S, Kelemen B, Pepsin M, Chow N, Mitchinson C, Ward M. Flow cytometric sorting of the filamentous fungus Trichoderma reesei for improved strains. Enzyme Microb Technol. 2010:47:335-41.

27. Pakula TM, Laxell M, Huuskonen A, Uusitalo J, Saloheimo M, Penttila $M$. The effects of drugs inhibiting protein secretion in the filamentous fungus Trichoderma reesei. Evidence for down-regulation of genes that encode secreted proteins in the stressed cells. J Biol Chem. 2003:278:45011-20.

28. Giese H, Kruithof $\mathrm{P}$, Meier $\mathrm{K}$, Sieben M, Antonov E, Hommes RWJ, Buchs J. Improvement and scale-down of a Trichoderma reesei shake flask protoco to microtiter plates enables high-throughput screening. J Biosci Bioeng. 2014:118:702-9.

29. Baird GS, Zacharias DA, Tsien RY. Biochemistry, mutagenesis, and oligomerization of DsRed, a red fluorescent protein from coral. Proc Natl Acad Sci USA. 2000;97:11984-9.

30. Kim YS, Jung HC, Pan JG. Bacterial cell surface display of an enzyme library for selective screening of improved cellulase variants. Appl Environ Microbiol. 2000;66:788-93.

31. Wen F, Sun J, Zhao H. Yeast surface display of trifunctional minicellulosomes for simultaneous saccharification and fermentation of cellulose to ethanol. Appl Environ Microbiol. 2010;76:1251-60.

32. Ouyang $H$, Chen $X$, Lu Y, Wilson IB, Tang G, Wang A, Jin C. One single basic amino acid at the omega-1 or omega-2 site is a signal that retains glycosylphosphatidylinositol-anchored protein in the plasma membrane of Aspergillus fumigatus. Eukaryot Cell. 2013;12:889-99.

33. Zhang $X$, Zhang XF, Li HP, Wang LY, Zhang C, Xing XH, Bao CY. Atmospheric and room temperature plasma (ARTP) as a new powerful mutagenesis tool. Appl Microbiol Biotechnol. 2014;98:5387-96.

34. Aro N, Ilmen M, Saloheimo A, Penttila M. ACEl of Trichoderma reesei is a repressor of cellulase and xylanase expression. Appl Environ Microbiol. 2003;69:56-65

35. Saloheimo M, Valkonen $M$, Penttila M. Activation mechanisms of the HAC1-mediated unfolded protein response in filamentous fungi. Mol Microbiol. 2003:47:1149-61.

36. Klein T, Niklas J, Heinzle E. Engineering the supply chain for protein production/secretion in yeasts and mammalian cells. J Ind Microbiol Biotechnol. 2015;42:453-64

37. Druzhinina IS, Kubicek CP. Genetic engineering of Trichoderma reesei cellulases and their production. Microb Biotechnol. 2017;10:1485-99.

38. Glass NL, Schmoll M, Cate JH, Coradetti S. Plant cell wall deconstruction by ascomycete fungi. Annu Rev Microbiol. 2013;67:477-98.

39. Zhang F, Carothers JM, Keasling JD. Design of a dynamic sensor-regulator system for production of chemicals and fuels derived from fatty acids. Nature Biotechnol. 2012;30:354-9.

40. Xiong D, Lu S, Wu J, Liang C, Wang W, Jin JM, Tang SY. Improving key enzyme activity in phenylpropanoid pathway with a designed biosensor. Metab Eng. 2017:40:115-23. 
41. Liu R, Chen L, Jiang YP, Zhou ZH, Zou G. Efficient genome editing in filamentous fungus Trichoderma reesei using the CRISPR/Cas9 system. Cell Discov. 2015;1:15007.

42. Seiboth B, Hakola S, Mach RL, Suominen PL, Kubicek CP. Role of four major cellulases in triggering of cellulase gene expression by cellulose in Trichoderma reesei. J Bacteriol. 1997;179:5318-20.

43. Ishida H, Matsumura K, Hata Y, Kawato A, Suginami K, Abe Y, Imayasu S, Ishishima E. Establishment of a hyper-protein production system in submerged Aspergillus oryzae culture under tyrosinase-encoding gene (melo) promoter control. Appl Microbiol Biotechnol. 2001;57:131-7.

44. O'Donnell D, Wang LP, Xu JF, Ridgway D, Gu TY, Moo-Young M. Enhanced heterologous protein production in Aspergillus niger through $\mathrm{pH}$ control of extracellular protease activity. Biochem Eng J. 2001;8:187-93.

45. Woodyer R, Simurdiak M, van der Donk WA, Zhao HM. Heterologous expression, purification, and characterization of a highly active xylose reductase from Neurospora crassa. Appl Environ Microb. 2005;71:1642-7.

46. Visser H, Joosten V, Punt PJ, Gusakov AV, Olson PT, Joosten R, Bartels J, Visser J, Sinitsyn AP, Emalfarb MA, et al. Development of a mature fungal technology and production platform for industrial enzymes based on a Myceliophthora thermophila isolate, previously known as Chrysosporium lucknowense C1. Ind Biotechnol. 2011;7:214-23.

47. Shao Z, Zhao H. DNA assembler, an in vivo genetic method for rapid construction of biochemical pathways. Nucleic Acids Res. 2009;37:e16.

48. Xu X, Li J, Shi P, Ji W, Liu B, Zhang Y, Yao B, Fan Y, Zhang W. The use of T-DNA insertional mutagenesis to improve cellulase production by the thermophilic fungus Humicola insolens Y1. Sci Rep. 2016;6:31108.
49. Gibson DG, Young L, Chuang RY, Venter JC, Hutchison CA, Smith HO. Enzymatic assembly of DNA molecules up to several hundred kilobases. Nat Methods. 2009;6:341-3.

50. Hartl L, Seiboth B. Sequential gene deletions in Hypocrea jecorina using a single blaster cassette. Curr Genet. 2005;48:204-11.

51. Penttila M, Nevalainen $H$, Ratto M, Salminen E, Knowles J. A versatile transformation system for the cellulolytic filamentous fungus Trichoderma reesei. Gene. 1987;61:155-64.

52. de Groot MJA, Bundock P, Hooykaas PJJ, Beijersbergen AGM. Agrobacterium tumefaciens-mediated transformation of filamentous fungi. Nat Biotechnol. 1998;16:839-42.

53. Solomon PS, Ipcho SVS, Hane JK, Tan KC, Oliver RP. A quantitative PCR approach to determine gene copy number. Fungal Genet Rep. 2008;55:5-8.

54. Vasara T, Keranen S, Penttila M, Saloheimo M. Characterisation of two 14-3-3 genes from Trichoderma reesei: interactions with yeast secretory pathway components. Biochim Biophys Acta. 2002;1590:27-40.

55. Veldhuisen G, Saloheimo M, Fiers MA, Punt PJ, Contreras R, Penttila M, van den Hondel CA. Isolation and analysis of functional homologues of the secretion-related SAR1 gene of Saccharomyces cerevisiae from Aspergillus niger and Trichoderma reesei. Mol Gen Genet. 1997;256:446-55.

56. Saloheimo M, Wang H, Valkonen M, Vasara T, Huuskonen A, Riikonen M, Pakula T, Ward M, Penttila M. Characterization of secretory genes ypt1/yptA and nsf1/nsfA from two filamentous fungi: induction of secretory pathway genes of Trichoderma reesei under secretion stress conditions. Appl Environ Microbiol. 2004;70:459-67.
Ready to submit your research? Choose BMC and benefit from:

- fast, convenient online submission

- thorough peer review by experienced researchers in your field

- rapid publication on acceptance

- support for research data, including large and complex data types

- gold Open Access which fosters wider collaboration and increased citations

- maximum visibility for your research: over $100 \mathrm{M}$ website views per year

At $\mathrm{BMC}$, research is always in progress.

Learn more biomedcentral.com/submissions 